\title{
Modelling the material and energy costs of the transition to low-carbon energy
}

\author{
Olivier Vidal(*), Hugo le Boulzec and Cyril François \\ Isterre, CNRS, Université Grenoble-Alpes - France
}

\begin{abstract}
Summary. - The evolution from 2000 to 2050 of the needs in concrete, steel, aluminium and copper to build the infrastructure of electricity generation is modelled for the scenarios of García-Olivares et al. (2012), Ecofys-WWF (2012) and the blue map scenario of the IEA (2010). A simple dynamic model is used to estimate the primary production, recycling and lost flows as well as the cumulative stocks of material to be produced, to go into the infrastructure and to be lost. The energy of material production is also estimated. When compared with the expected evolution of global material and energy demands, the modelling results suggest that i) the transition to low-carbon energies implies a substantial increase of raw materials and energy consumption, ii) the shorter lifetime of wind and solar facilities and the loss of recycling implies that the total amount of metal to be produced during the deployment of the infrastructure of energy is significantly higher than their amount stocked in the infrastructure, and iii) the needs in materials and energy will occur in a period of expected increase of primary metal consumption at the world scale and limited potential of recycling.
\end{abstract}

\section{Introduction}

Meeting a growing demand for energy while reducing greenhouse gas emissions is a crucial challenge of the 21st century. The European Commission aims to reach a share of renewable energy of at least $27 \%$ of EU energy consumption by 2030 and the COP21 Paris agreement on climate change targets reaching the "carbon neutrality" worldwide

$\left(^{*}\right)$ E-mail: Olivier.Vidal@univ-grenoble-alpes.fr 
by 2050. To achieve these objectives, it is necessary to transform within 40 years the existing fossil-fuels-based system of energy generation, transportation, storage, distribution and use. Large infrastructures of energy generation with a material intensity significantly larger than that of fossil fuels power plants are required to capture renewable but diluted energy [1-6]. The latest generations of $>5 \mathrm{MW}$ off-shore wind turbines with their foundation contain about $1000 \mathrm{t}$ of steel and they require wiring network and grounding systems that consume up to 9.6 tons of copper per MW [7]. This corresponds to steel intensities 2 to 6 times larger than fossil fuel power plants and copper intensities 4 to 13 times larger [4]. The same observation is made for many other mineral resources including cement, aggregates, aluminium, and a variety of rare metals and other "critical" raw materials like REE, platinium group metals, etc. [8]. The production of all these materials is not neutral and it requires high amounts of energy. At present, about $10 \%$ of the world energy demand is used for cement and steel productions alone. It appears thus that the transition to renewable energy will be a source of energy and material overconsumption during the next 40 years. An estimation of the needs must be made to evaluate the best deployment options in regard to the actual and forecasted global supply of material and energy for the next decades.

In the following, we propose a quite simple dynamic modelling of material flows and stocks and energy flows. It is used to estimate the needs in primary and recycled material for the future infrastructure of electricity generation for three contrasted energy scenarios. The results are then compared to the needs of matter and energy at the global scale. Our study focuses on the case of steel, cement, aluminium and copper, which are the major and non-substitutable materials carrying the most important part of embodied energy in the energy production facilities. Moreover, the historical consumption and production of these raw materials are well documented since several decades, and their future needs can be estimated in a relatively reliable way as it poorly depends on technological innovation (in contrast to rare metals used in high technologies metals).

\section{1. - The considered scenarios of energy}

Many scenarios of the future energy demand have been published during the last decades, which foresee contrasted evolutions in the shares of conventional and renewables capacities. In the following, the IEA blue map scenario (BM) from [9] was selected because it is rather conservative in anticipating that about $40 \%$ of the global electricity (36500 TWh/yr in 2050) will be produced from renewable sources. The Ecofys-WWF scenario (WWF) from [10] is more ambitious. It assumes a $100 \%$ renewable electricity production in 2050, produced with a mix of solar PV and concentrated solar power (CSP) technologies, wind turbines and hydropower (fig. 1). The WWF scenario is based on the sobriety of use and assumes a strong reduction of global energy consumption down to 260 EJ in 2050 (393 EJ in 2015; see [11]). Similarly, it assumes a limited increase of electricity consumption to $29000 \mathrm{TWh} / \mathrm{yr}$ in 2050 (36500 TWh/yr for BM). The last considered scenario (GO) proposed by García-Olivares et al. [2] assumes that the unique source of energy in 2030 is electricity produced by wind turbines, CSP and hydropower. 


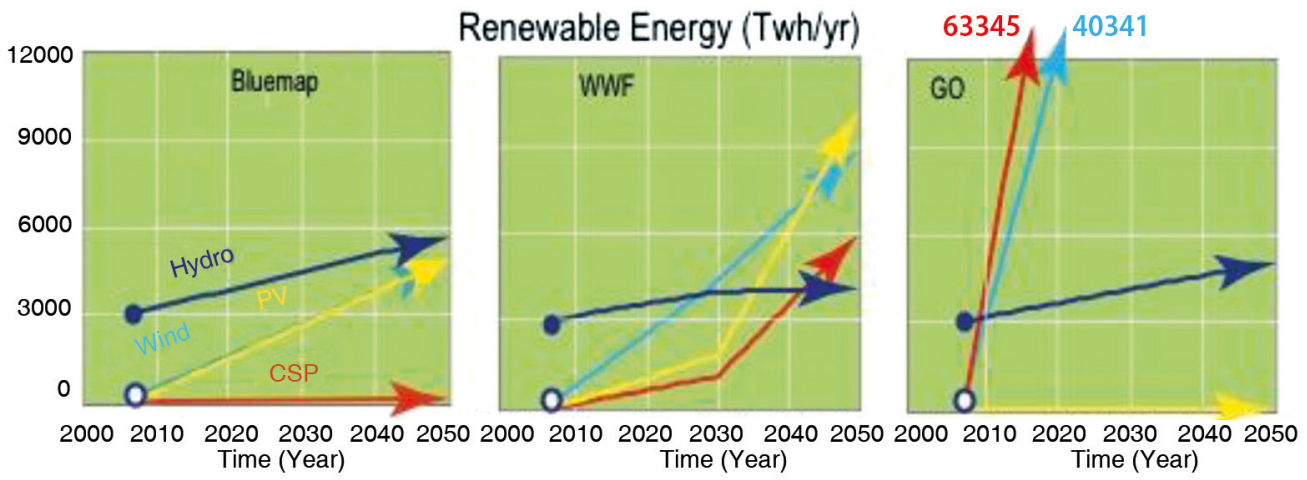

Fossil Energy (Twh/yr)
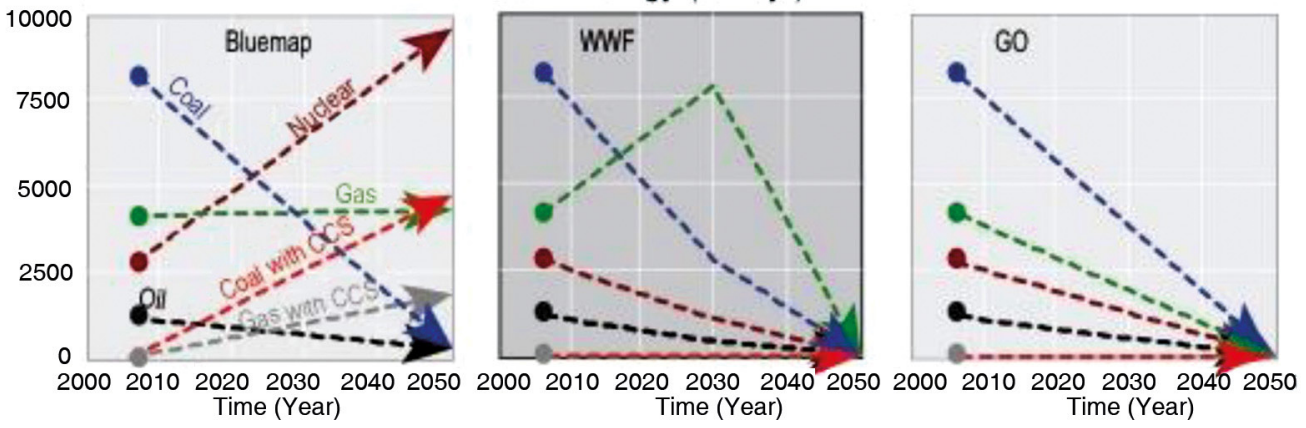

Fig. 1. - Evolution of the energy mix for the blue map [9], Ecofys-WWF [10] and García-Olivares et al. [2] (GO) scenarios.

The global demand in electricity will reach the enormous value of $108000 \mathrm{TWh} / \mathrm{yr}$ in 2030. Such an evolution is clearly unrealistic, but the GO scenario remains interesting because it provides an upper limit in raw materials demand for the transition to lowcarbon energy. In order to be more realistic, we have considered that the scenario is achieved in 2050 instead of in 2030 .

\section{2. - The dynamic model}

The value chain from primary extraction, use, end-of-life and recycling has been modelled as shown in fig. 2. Three types of power generation infrastructures have been considered on the basis of their lifetime. The lifetime of wind and solar power sources is assumed to be 20 years, 40 years for coal, gas and oil-fired power plants, and 60 years for nuclear power plants. For each type of installation, the stock in tons of "Primary raw material in the infrastructure" is supplied by the flow in tons/year of "primary production", and the stock of "recycled metal in the infrastructure" is supplied by the "recycling" flow. The infrastructure manufactured at $t_{0}$ reaches its end of life in $t_{0}+\Delta t$ where $\Delta t=$ lifetime $(20,40$ or 60 years). The stock "primary raw material in the in- 


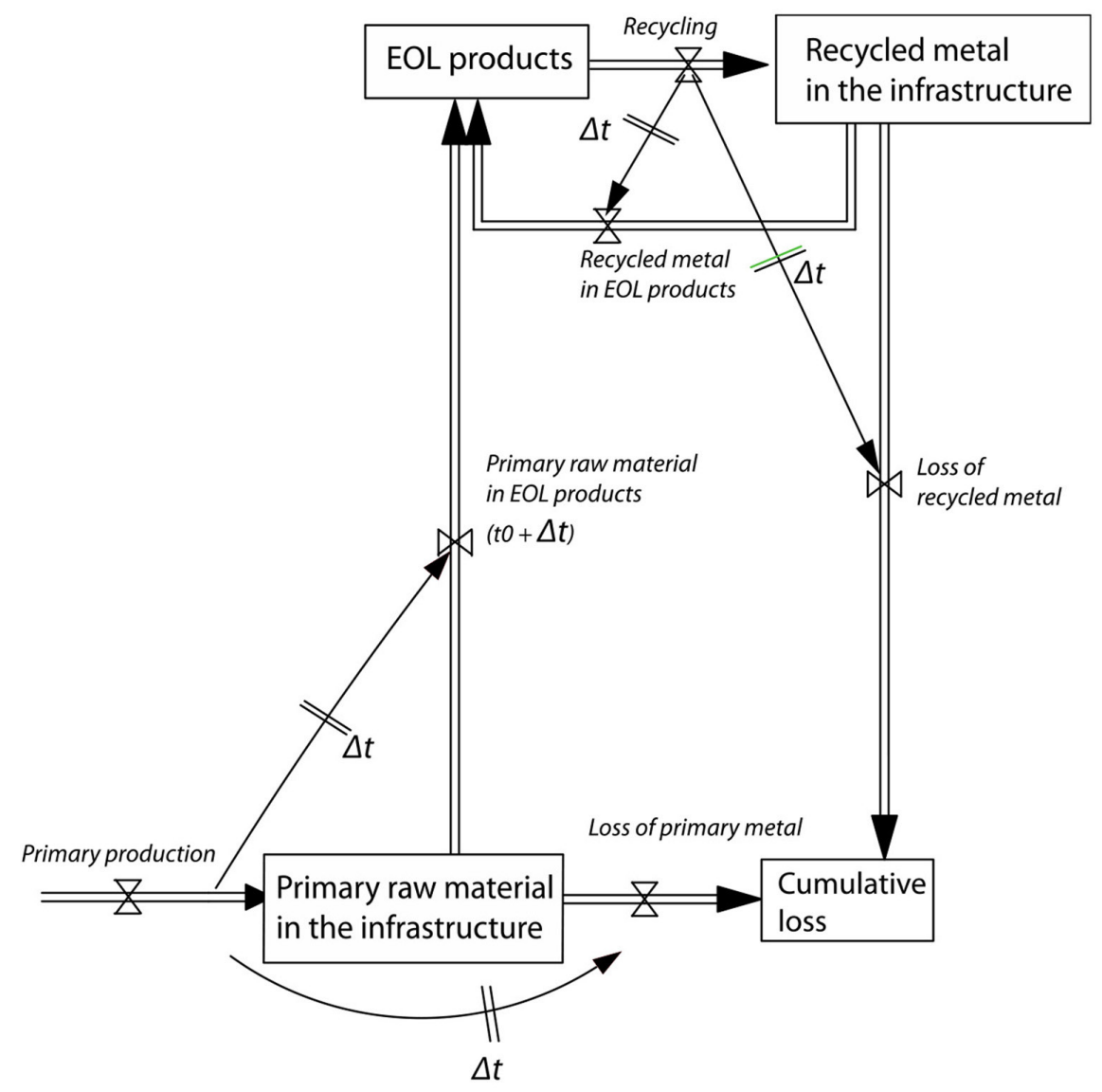

Fig. 2. - Schematic view of the model used to estimate the stocks and flows of matter during the construction and maintenance of the infrastructure of electricity generation [4].

frastructure" is then reduced by the outgoing flow of "primary raw material in EOL products", which represents the flow of primary raw materials from the working infrastructure to the stock of end-of-life products (EOL). This $t_{0}+\Delta t$ flow is equal to the "primary production" flow at $t_{0}$ multiplied by a collection rate $(\mathrm{CR})$. The rest of the material is lost at $t_{0}+\Delta t$ through the flow "loss of primary metal" = "primary production" $\times(1-\mathrm{CR})$. The stock of "EOL products" is also supplied by the already-recycled metal flow entering a new recycling loop ("recycled metal in EOL products"). At $t_{0}+\Delta t$, this "recycled metal in EOL products" flow is equal to the "recycling" flow at $t_{0}$ multiplied by $\mathrm{CR}$. We have assumed that all the EOL products are immediately recycled, so that this stock is empty. This assumption implies that the collection rate (CR) used in the present study encompasses both the true collection and recycling rates of EOL products.

The model is run from 1900 to 2100 , assuming that i) the installed capacities of 
TABLE I. - Energy consumed for the production of concrete, steel, aluminium and copper [12], and collection rates (CR) of metals from the infrastructure of energy or for all goods at the global scale.

\begin{tabular}{|c|c|c|c|c|}
\hline & 2010 & 2030 & 2050 & $2050 / 2010$ \\
\hline \multicolumn{5}{|c|}{ Primary energy of production $(\mathrm{MWh} / \mathrm{t})$} \\
\hline Concrete & 0.3 & 0.2 & 0.2 & 0.84 \\
\hline Steel & 6.11 & 5.1 & 4.2 & 0.68 \\
\hline $\mathrm{Al}$ & 23.6 & 20.8 & 18.1 & 0.77 \\
\hline $\mathrm{Cu}$ & 8.3 & 8.3 & 8.3 & 1.00 \\
\hline \multicolumn{5}{|c|}{ Recycling energy $(\mathrm{MWh} / \mathrm{t})$} \\
\hline Steel & 1.9 & 1.5 & 1.1 & 0.57 \\
\hline $\mathrm{Al}$ & 2.4 & 2.1 & 1.8 & 0.77 \\
\hline $\mathrm{Cu}$ & 4.2 & 4.2 & 4.2 & 1.00 \\
\hline \multicolumn{5}{|c|}{ CR of metals in the infrastructure (\%) } \\
\hline Steel & 0.70 & 0.70 & 0.70 & 1.00 \\
\hline $\mathrm{Al}$ & 0.70 & 0.70 & 0.70 & 1.00 \\
\hline $\mathrm{Cu}$ & 0.70 & 0.70 & 0.70 & 1.00 \\
\hline \multicolumn{5}{|c|}{ Global CR (\%) } \\
\hline Steel & 0.65 & 0.67 & 0.68 & 0.73 \\
\hline $\mathrm{Al}$ & 0.43 & 0.47 & 0.51 & 0.60 \\
\hline $\mathrm{Cu}$ & 0.43 & 0.47 & 0.51 & 0.60 \\
\hline
\end{tabular}

nuclear power stations increase linearly from $10 \mathrm{GW}$ in 1950 to $609 \mathrm{GW}$ in 2010, ii) the installed capacities of other fossil fuel power stations and hydropower plants increase exponentially at a constant rate of 3\%/yr between 1900 and 2010, and iii) the installed capacities remain constant after 2050.

The amounts of material in the electricity-generation infrastructures are calculated using the material intensities in tons per MW installed capacity listed in table 5.1 of [4]. The energy required to produce the materials are calculated using the values in energy/mass from [12] for primary production and recycling, which are listed in MWh/t in table I. The collection rates $(\mathrm{CR})$ of all metals from the electricity-generation infrastructure have been set at $70 \%$.

\section{3. - Concrete, steel, aluminium and copper requirements for the future electricity-generation infrastructure}

For the three scenarios, the needs of copper for renewables represent more than $85 \%$ of the total needs (i.e. including the other sources of electricity generation). For the blue map scenario, the cumulative stock of primary copper in the infrastructure of electricity generation is about $39 \mathrm{Mt}$ in 2050 (24 Mt primary and $15 \mathrm{Mt}$ recycled, see the graph in the 

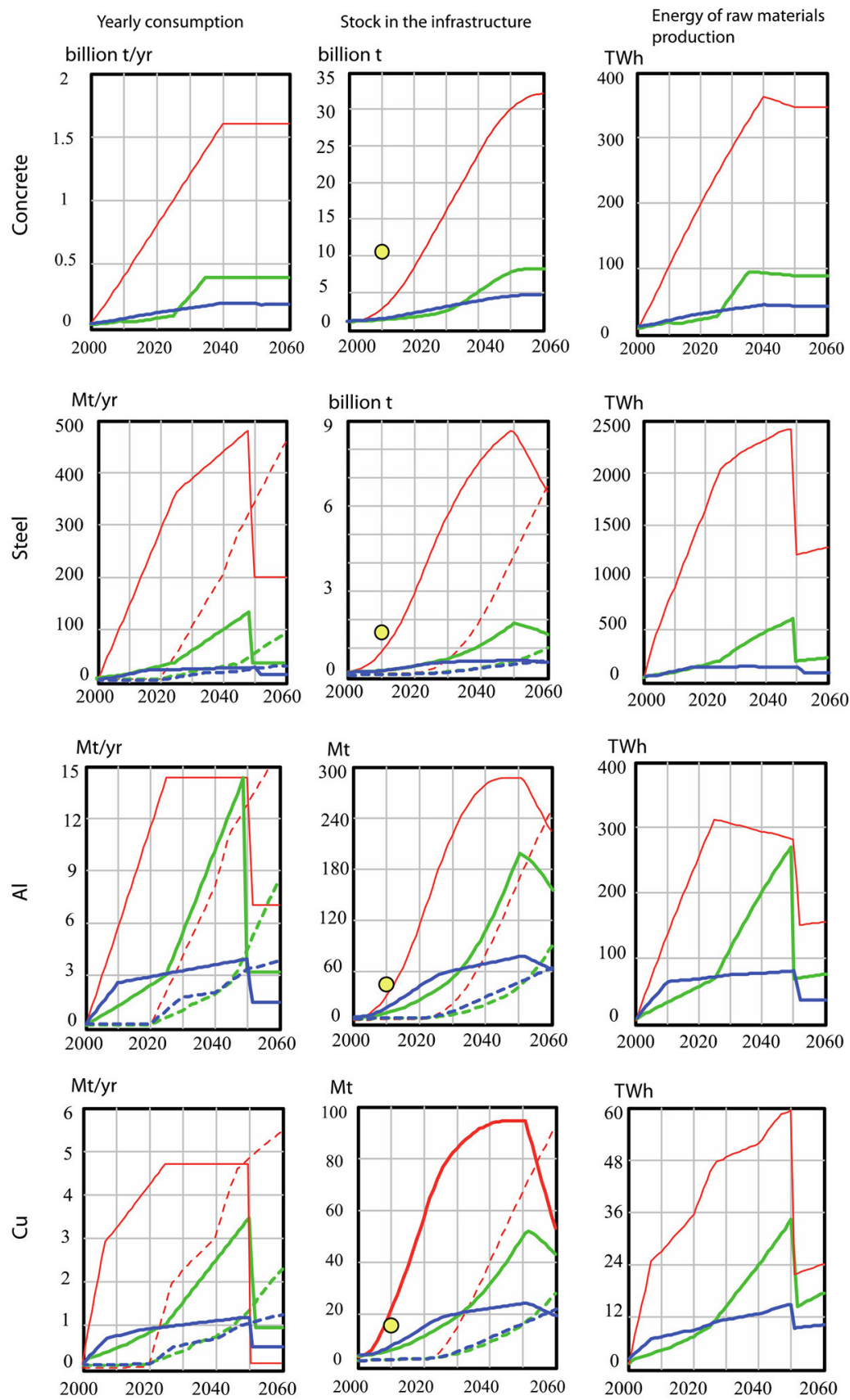

Fig. 3. - Annual consumption (first column) and cumulative requirements (second column) of primary materials (solid lines) and recycled materials (dotted lines) for the deployment of the infrastructure of electricity production. The third column shows the annual energy consumed for primary production and recycling. The red, green and blue lines show the GO, WWF and BM scenarios, respectively. Yellow dots: annual global production. 
second column and last row of fig. 3). However, $30 \%$ of copper is lost during recycling, so that the true amount of copper to produce by 2050 is about $55 \mathrm{Mt}$. This estimated value is almost two times higher than that estimated by [5] for the same scenario (29 Mt). The cumulative amount of copper increases to $90 \mathrm{Mt}$ for the WWF scenario (50 Mt primary, $22 \mathrm{Mt}$ recycled and $18 \mathrm{Mt}$ lost) and $205 \mathrm{Mt}$ for the GO scenario (55 Mt primary, $90 \mathrm{Mt}$ recycled and $60 \mathrm{Mt}$ lost), in fair agreement with García-Olivares et al.'s [2] own estimates (183 Mt). Finally, the BM, WWF and GO scenarios need 2, 4 and 10 years of the present $\mathrm{Cu}$ global production, respectively, which will have to be allocated to the infrastructure of electricity until 2050. In the BM scenario, the annual production of copper assigned to the infrastructure of electricity generation peaks at $2.2 \mathrm{Mt} / \mathrm{yr}(1.2 \mathrm{Mt} / \mathrm{yr}$ of primary $\mathrm{Cu})$ at the end of the deployment period. It drops to $1.6 \mathrm{Mt} / \mathrm{yr}(0.5 \mathrm{Mt} / \mathrm{yr}$ primary) after 2050, which is the flow of virgin $\mathrm{Cu}$ required to maintain the infrastructure and balance the loss of recycling. For the GO scenario, the yearly consumption reaches $9 \mathrm{Mt}$ (4.5 Mt/yr primary) and it drops to $5 \mathrm{Mt} /$ year (1 Mt/yr primary) after 2050.

Following our assumption that $70 \%$ of copper is recycled, from the infrastructure, primary copper consumption between 2030 and 2050 ranges from 1 to $4.5 \mathrm{Mt} / \mathrm{yr}$ for the three considered scenarios. This yearly consumption is equivalent to 5 to $20 \%$ of the present global production. García-Olivares et al. [2] estimated that the share of copper in the infrastructure of electricity generation represents $55 \%$ of the total amount required to achieve the full shift from fossil to renewable energy. The cumulative amount of primary copper to be produced until 2050 could be therefore as high as $270 \mathrm{Mt}$ for the GO scenario and $145 \mathrm{Mt}$ for the WWF scenario, which is equivalent to 7 to 13 times the present annual global production, and 20 to $40 \%$ of the known copper reserves. However, it is emphasized that a significant portion of the needed metals comes from recycling. The most exigent scenario (GO) requires $205 \mathrm{Mt}$ copper, but if the infrastructure is recycled for the same use, "only" half of this amount is primary copper.

The cumulative production and consumption of steel and aluminium show trends similar to those of copper (fig. 3). About $500 \mathrm{Mt}$ aluminium are necessary to achieve the GO scenario, $230 \mathrm{Mt}$ for the WWF scenario and $120 \mathrm{Mt}$ for the blue map scenario. These amounts represent 8,4 and 2 years of the present global production, respectively. The yearly consumptions of primary $\mathrm{Al}$ and steel between 2030 and 2050 represent 5\% $(\mathrm{BM})$ to $25 \%(\mathrm{GO})$ of the present global productions. For the GO scenario, our estimated amounts of steel incorporated in the infrastructure (13000 Mt) are much larger than García-Olivares et al.'s own estimates (3800 Mt). The difference stems from the use of different steel contents per MW of installed CSP facilities and to a lesser extend from wind turbines. The steel content used in the present study for CSP technologies (563t/MW) was estimated by [4] as an average of the literature data and it is similar to the average of the data reported by [5]. In contrast, García-Olivares et al. used data representative of Andasol 1 only (180t/MW). Similarly, the steel content of wind turbines estimated by [4] (166 t/MW) considers a range of on-shore and off-shore installations, while García-Olivares et al. used the value of Vesta V-90 (3 MW) turbine only $(132 \mathrm{t} / \mathrm{MW})$. As for copper, a strong drop in primary metal consumption occurs after 2050, when the capacity of the installed infrastructure is assumed to remain constant. 
The primary metal consumption after 2050 remains however significant (200 Mt/yr, see fig. 3), because the short lifetime of solar and wind infrastructures implies rapid renewal and high losses of material during collection and recycling of the end-of-life infrastructure. For the WWF and GO scenarios, the yearly recycling of metals from the infrastructure after 2050 oscillates around values equivalent to the present global recycling from all manufactured products. To achieve this goal, the present recycling capacities will have to be scaled up significantly.

\section{4. - Generated and consumed energy}

The consumed energy to produce the raw materials for the electricity generation infrastructure increases until 2050, it drops sharply after 2050 and remains almost constant until 2100 (fig. 3, last column). For the GO scenario, this energy rises from $63 \mathrm{TWh} / \mathrm{yr}$ in 2000 to $3050 \mathrm{TWh} / \mathrm{yr}$ in 2050, and it stabilizes at $1650 \mathrm{TWh} / \mathrm{yr}$ after 2050. The energy consumed to produce the materials of the infrastructure is thus multiplied by 50 in 50 years, and it is 25 times higher after 2050 than in 2000, even if the installed capacity remains constant. This is due to the fast replacement of wind and solar facilities, which are assumed to have a twenty-year lifetime. Nevertheless, the energy consumed to produce the materials represent only from 2 to $4.5 \%$ of the annual energy generated by the infrastructure between 2010 and 2050 and 1.5\% after 2050. For the WWF scenario, the energy consumption increases from 63 to $950 \mathrm{TWh} / \mathrm{yr}$ between 2000 and 2050 (between $0.4 \%$ and $3 \%$ of the produced energy) and stabilizes at $400 \mathrm{TWh} / \mathrm{yr}$ after 2050 . For the blue map scenario, the consumed energy increases to $250 \mathrm{TWh} / \mathrm{yr}$ in 2050 and remains below $1 \%$ of the produced energy. For the three scenarios, the energy used to produce the concrete, aluminium, copper and steel is less than $5 \%$ of the energy generated by the infrastructure. This fraction may appear small, but it omits the energy to produce other components than the generation system of the infrastructure, as well as the energy consumed by the numerous industrial processes that transform the raw materials into complex machines, the construction of the infrastructure, its maintenance and repair operations. Whatever the true amount of energy consumed to build the infrastructure of energy, our results show that greater amounts of energy are needed for the construction and maintenance of fully decarbonized electricity generation infrastructures than for an infrastructure maintaining a fraction of the electricity produced from fossil fuels. The shift to renewables will thus be a source of material and energy overconsumption. The WWF scenario assumes a significant reduction of global energy demand down to $260 \mathrm{EJ} / \mathrm{yr}(72000 \mathrm{TWh} / \mathrm{yr})$ in 2050 from $393 \mathrm{EJ} / \mathrm{yr}$ in 2015 [11]. Is this reduction of final energy compatible with the increasing demand of energy at the global scale? This point is discussed below.

\section{5. - Comparison with future global trends}

The results presented above can be compared with the global production of concrete, steel, aluminium and copper as well as the global energy consumed for their supply. At 
this end, the model shown in fig. 1 was used and run for each commodity assuming an average lifetime for all goods produced globally. This allowed us to infer the evolution of primary and secondary productions, as well as the energy of production at the global scale. The lifetime of iron (steel), copper and aluminium at the global scale were assumed to be 30 years. The CR of steel was estimated in order to reproduce the 1900 to 2015 production data of crude steel reported by the USGS and the share of primary iron (pig iron) and global scrap steel consumption reported by the AME group [13]. Between 2007 and 2050, the primary production and recycling of steel were assumed to increase from $1300 \mathrm{Mt}$ and $400 \mathrm{Mt}$, respectively, to $2200 \mathrm{Mt}$ and $1000 \mathrm{Mt}$, respectively. To reproduce these trends, the collection rate of steel should increase from 0.65 in 2000 and to 0.68 in 2100 (table I). The collection rate of copper was constrained to 0.43 for the period 1930 to 2015 in order to reproduce the yearly amount of copper produced from old scrap since 1960 [14] and the amount of primary copper produced since 1900 reported by the USGS [15]. It was more difficult to find reliable data for aluminium and we assumed a collection rate similar to that of copper. The future primary copper production was assumed to follow the trend estimated by [16] and the future production of steel until 2050 corresponds to the base case scenario of [13], which is consistent with the BM scenario. For aluminium, we assumed a constant growth rate of production that reaches $150 \mathrm{Mt} /$ year in 2050, in agreement with the estimates of [9] ranging from 142 to $190 \mathrm{Mt} / \mathrm{yr}$. The growth rate of concrete production was assumed to increase to $7 \mathrm{Gt} /$ year in 2050, which is slightly higher than the IEA estimates ranging between 5 and $6 \mathrm{Gt} /$ year $[9]$.

For the BM scenario, the proportions of metals for the infrastructure of electricity are 0.8 to $3 \%$ of the global production for steel, 1.5 to $6 \%$ of aluminium production and 2 to $5 \%$ of copper production. These proportions are much higher for the WWF scenario (up to $9.5 \%$ for steel, $15 \%$ for aluminium and 10\% for copper between 2040 and 2050), and become huge for the GO scenario ( $9 \%$ for aluminium and $25 \%$ for steel and copper between 2025 and 2050). In the case of copper, the maximum consumption of metals by the infrastructure of electricity is reached at the time of the primary production peak forecasted by [16] and [17]. If these copper peaks occur, the implementation of the WWF and GO scenarios might be compromised by the availability of primary copper. In any case, a significant proportion of the global copper production should be reserved for the generation and use of electricity, and/or substitutes to copper will have to be found. The same trends are observed for the recycled portion. Between 2025 and 2075, 20 to $30 \%$ of steel, 10 to $20 \%$ of aluminium and 30 to $50 \%$ of copper recycled every year should be used for the infrastructure of electricity according to the GO scenario. It must be emphasized that a significant increase of recycled metal is not possible, because the amount of recycled metal is primarily constrained by the flow of metals to the EOL products stock. This flow corresponds to the total production 30 years earlier multiplied by the collecting rate. About $850 \mathrm{Mt}$ of crude steel has been produced in 2000, while the expected demand in 2030 will be about $2300 \mathrm{Mt}$. The share of recycled steel in total production will thus be less than $35 \%$ in 2030 . Actually, the true share of recycled steel in total production is calculated to decrease down to $25 \%$ between 2000 and 2010 and to 
remain stable until 2030. Steel recycling and the ratio recycled/total should then rapidly increase to reach $45 \%$ in 2050. Similar trends are observed for aluminium and copper. In the same time, the substantial increase of (recycled metal)/(total production) ratios after 2030 is accompanied by an equally significant decrease in raw materials energy consumption.

The huge needs in commodities for the GO scenario result from the enormous renewable production of electricity, which reaches $109000 \mathrm{TWh} / \mathrm{yr}$ in 2050. In comparison, electricity productions in the WWF and BM scenarios are $29000 \mathrm{TWh} / \mathrm{yr}$ and $36500 \mathrm{TWh} / \mathrm{yr}$, respectively. The WWF scenario also assumes a decline in final global energy from $102000 \mathrm{TWh} / \mathrm{yr}$ in 2010 [11] to $72000 \mathrm{TWh} / \mathrm{yr}$ in 2050. For the energy efficiency improvements considered in table I, the energy consumed by the global production of cement, aluminium and steel is $10700 \mathrm{TWh} / \mathrm{yr}$ in 2010 and $17200 \mathrm{TWh} / \mathrm{yr}$ in 2050 . It follows that the share of global final energy used to produce these commodities increases from $10 \%$ to $16 \%$ between 2010 and 2050 in the BM and GO scenario. It increases from $10 \%$ to $24 \%$ over the same period of time in the WWF scenario. If we assume that the industry worldwide will consume one third of the final energy in 2050 (as in 2015), 70\% of the industrial consumption of energy should be assigned to the production of cement, steel and aluminium for the WWF scenario (fig. 4). This is quite unrealistic.

Apart from the raw materials availability, the WWF scenario thus raises the problem of available energy for the future global production of mineral commodities. To cope with the problem, the authors of the WWF scenarios assumed a 50 to $60 \%$ reduction of energy consumed for the production of cement, steel and aluminium. Part of this reduction can be achieved through an increase of the ratio recycling/primary production of metals, because recycling is much less energy demanding than primary production (see table I). However, as stated above, this ratio will remain unchanged until 2030, because the long lifetime of metals in finished goods implies that their available amounts for recycling are at best 50 to $80 \%$ of their primary production 30 to 50 years earlier. In a period of strong growth of metal consumption, the available amounts of old scraps are therefore much less than total production. Another way to reduce the energy of production is to significantly improve the energy efficiency. However, a 50 to $60 \%$ reduction of embodied energy of metals production in the next 40 years will be very difficult to achieve. In the past 40 years, the global average energy requirements for production of pig iron from ore and aluminium smelting have been lowered by 25 to $30 \%$ only, and steel and aluminium are already close to $60 \%$ efficiency relative to their thermodynamic limits [18]. Further energy savings are more and more difficult when approaching these thermodynamic limits. For the 16 to $32 \%$ energy improvement considered in the present study (table I), the global final energy must remain above $110000 \mathrm{TWh} / \mathrm{yr}$ in 2050 in order to keep a constant proportion of energy consumed by the production of concrete, steel and aluminium below $15 \%$. This value is $40 \%$ higher than that envisaged in the WWF scenario, which is extraordinary low compared to the majority of published values, which range between 110000 and $250000 \mathrm{TWh} / \mathrm{yr}$. The final energy consumption assumed by WWF is only one third of the value of the reference case proposed by the International Energy Outlook $2016(815 \mathrm{PJ} / \mathrm{yr}=238800 \mathrm{TWh} / \mathrm{yr})$. 


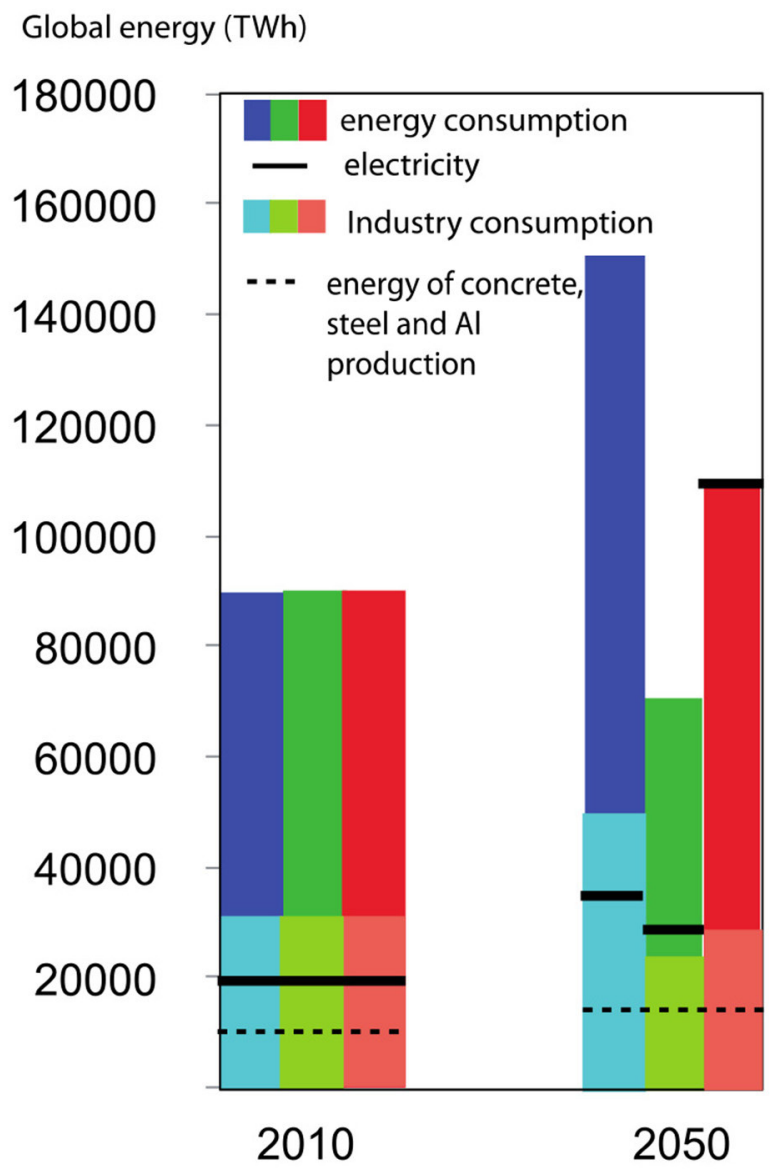

Fig. 4. - Global energy demand and electricity consumptions for the scenarios GO (red), WWF (green) and BM (blue). The industry consumption (black line) is estimated to be $30 \%$ of the global energy consumption. The energy consumed for the global production of concrete, steel and $\mathrm{Al}$ (dashed lines) is calculated from the relative proportions of primary and secondary production derived from dynamic modelling multiplied by the energies of production listed in table I.

\section{Conclusion}

Contrasting needs in raw materials and energy are estimated for the different energy scenarios used in the present study. This reflects the diversity of assumed energy mixes and installed capacities. The huge amount of raw materials required by the scenario GO makes it unrealistic to achieve in a short time. The WWF scenario is less exigent in terms of materials requirements, but the very low final energy production in 2050 is also unrealistic compared to the expected demand. Actually, the needs for the WWF scenario are similar to those of the GO scenario if the capacity to be installed is scaled up to the same value of the final energy. It must be emphasized that our estimates 
are fraught with large uncertainties because the variability of metal contents reported in the literature for the different kinds of electricity generation is equally large. This was illustrated by the differences discussed above for the steel content of CSP facilities, but the same uncertainties exist for all technologies and commodities. It is also possible that the energy efficiency of mineral resources production increases more than we have assumed in this study. Having said that, at least three qualitative conclusions can be drawn from the results of dynamic modelling:

1) With the current technologies, the transition to low-carbon energies implies a substantial increase in base materials consumption such as concrete, steel, aluminium and copper. This result is in line with previous estimates [1-8] and studies focusing on critical metals $[19,20]$. The consumed raw materials and energy are maximum during the building of the new infrastructure of energy, but they remain significant after this period to maintain and renew the wind and solar infrastructures of with a short lifetime.

2) The results of modelling show that i) the total amount of metal to produce during the deployment of the infrastructure of energy is significantly higher than the cumulative amount stocked in the infrastructure. This is due to the losses during recycling. Assuming a twenty-year lifetime for the renewables infrastructure and $\mathrm{CR}=0.7$, about $30 \%$ of the total copper production is lost by 2050 , and $50 \%$ is lost by 2100 , which will have to be balanced by primary extraction; ii) a significant portion of metals in the infrastructure is supplied by the recycling of the infrastructure. Therefore, the cumulative amount of metals in the infrastructure cannot be interpreted in terms of primary resources consumption. Dynamic modelling is necessary to estimate the true amount of primary metal and other resources required to build the infrastructure. Since the relative proportions of recycled-to-virgin metals as well as the energy mixes both change with time, dynamic modelling should be coupled with ACV analyses to correctly estimate the impacts of the energy transition.

3) The needs in materials and energy will occur in a period of expected increase of primary metal consumption at the world scale and limited potential of recycling. The supply of metals from recycling is expected to increase but it will not become higher than primary supply before the full shift to renewable energy.

More work is necessary to reach a comprehensive estimate covering the needs in mineral resources and energy from other sectors of energy such as the storage, distribution and use of electricity for applications that traditionally used fossil fuels, (transport, heating). Cement, steel, aluminium and copper are hardly substitutable and bear the most important part of the energy consumed for the production of mineral resources. The supply and impacts of supply of these basic raw materials that do not present any sign of scarcity yet it is an issue as important as the supply of the so-called "critical elements" produced in much lower quantities and whose use is likely to evolve fast with technical innovation. 
This work was supported by the project SURFER financed by "Agence de l'Environnement et de da Maitrise de l'Energie (ADEME).

\section{REFERENCES}

[1] Kleijn R., van der Voet E. and Kramer G. J. et al., "Metal requirements of lowcarbon power generation", Energy, 36 (2011) 5640.

[2] García-Olivares A., Ballabrera-Poy J. and García-Ladona E., "A global renewable mix with proven technologies and common materials", Energy Policy, 41 (2012) 561.

[3] Vidal O., Goffé B. and Arndt N., "Metals for a low-carbon society", Nat. Geosci., 6 (2013) 894.

[4] Vidal O., Mineral resources and energy (ISTE and Elsevier edition) 2017.

[5] Hertwich E. G., Gibon T. and Bouman E. A., "Integrated life-cycle assessment of electricity-supply scenarios confirms global environmental benefit of low-carbon technologies", Proc. Natl. Acad. Sci. U.S.A., 112 (2015) 6277.

[6] The World Bank: The Growing Role of Minerals and Metals for a Low Carbon Future (World Bank Publications) 2017.

[7] FAlCONer I., "Metals required for the UK's low carbon energy system: The case of copper usage in wind farms", Master's dissertation, University of Exeter, 2009.

[8] KLEIJN R., "Materials and energy: a story of linkages, material requirements of new energy technologies, resource scarcity and interconnected material flows", PhD thesis, Leiden University, Netherlands, 2012.

[9] International Energy Agency (IEA), Energy Technology Perspectives 2010: Scenarios and Strategies to 2050. Paris, France, 2010b, http://www.iea.org/publications/ freepublications/publication/name, 26100, en.html.

[10] Ecofys-WWF, The Energy Report 100\% Renewable Energy by 2050 (World Wide Fund for Nature (WWF), Gland, Switzerland) 2012.

[11] IEA Sankey diagrams: http://www.iea.org/Sankey/index.html\#?c=World\&s=Final\%20 consumption.

[12] Birat J.-P., Chiappini M. and Ryman C. et al., "Cooperation and competition among structural materials", Rev. Métallur., 110 (2014) 97.

[13] AME: http://www.ame.com.au/Website/FeatureArticleDetail.aspx?faId=12.

[14] Glöser S., Soulier M. and Tercero Espinoza L. A., "Dynamic Analysis of Global Copper Flows. Global Stocks, Postconsumer Material Flows, Recycling Indicators, and Uncertainty Evaluation", Environ. Sci. Technol., 47 (2013) 6564.

[15] Kelly T. D. and Matos G. R., Historical statistics for mineral and material commodities in the United States, U.S. Geological Survey Data Series 140 (USGS) open-life report 01006, 2014 https://minerals.usgs.gov/minerals/pubs/historical-statistics/.

[16] Northey S., Mohr S. and Mudd G. M. et al., "Modelling future copper ore grade decline based on a detailed assessment of copper resources and mining", Resour. Conserv. Recycl., 83 (2014) 190.

[17] Sverdrup H. U., Ragnasdottir K. A. and Koca D., "On modelling the global copper mining rates, market supply, copperprice and the end of copper reserves", Resour. Conserv. Recycl., 87 (2014) 158. 
[18] Gutowski T. G., Sahni S. and Allwood J. M., "The energy required to produce materials: constraints on energy-intensity improvements, parameters of demand", Philos. Trans. R. Soc. A, 371 (2013) 2012003 Available at: http://dx.doi.org/10.1098/rsta. 2012.0003.

[19] Öhrlund I., "Science and Technology Options Assessment, Future Metal Demand from Photovoltaic Cells and Wind Turbines, Investigating the Potential Risk of Disabling a Shift to Renewable Energy" (Science and Technology Options Assessment (STOA), Brussels) 2012. Available at: http://go.nature.com/VUDs7V.

[20] Moss R. L., Tzimas E. and Willis P. et al., "Critical metals in the path towards the decarbonisation of the EU energy sector, Assessing rare metals as supply-chain bottlenecks in low-carbon energy technologies", JERC Pub. No JRC65592, EUR 24884 EN, Joint Research Centre, 2013. Available at: http://publications . jrc.ec. europa .eu/ repository/handle/111111111/22726. 